\title{
Theory and Neutrons Combine to Reveal A Family of Layered Perovskites Without Inversion Symmetry
}

Tong Zhu, Toby Cohen, Alexandra S. Gibbs, Weiguo Zhang, P. Shiv Halasyamani, Michael A. Hayward" and Nicole A. Benedek ${ }^{*}$

\section{Supporting Information}

\section{Structural characterization of $\mathrm{CsNdTa}_{2} \mathrm{O}_{7}, \mathrm{RbNdNb}_{2} \mathrm{O}_{7}$ and $\mathrm{RbNdTa}_{2} \mathrm{O}_{7}$ using synchrotron $\mathrm{X}$-ray powder diffraction data vs. neutron powder diffraction data.}

Table S1. Fitting statistics from the structural refinement of $\mathrm{CsNdTa}_{2} \mathrm{O}_{7}$ against synchrotron X-ray and neutron powder diffraction data.

Table S2. Fitting statistics from the structural refinement of $\mathrm{RbNdNb}_{2} \mathrm{O}_{7}$ against synchrotron X-ray and neutron powder diffraction data.

Table S3. Fitting statistics from the structural refinement of $\mathrm{RbNdTa}_{2} \mathrm{O}_{7}$ against synchrotron X-ray and neutron powder diffraction data.

Figure S1. Observed calculated and difference plots from the structural refinement of $\mathrm{CsNdTa}_{2} \mathrm{O}_{7}$ against Synchrotron X-ray powder diffraction data. Top and middle plots show fits using a $P 2{ }_{1}$ am model. For comparison the bottom plot shows a fit using an $12 \mathrm{~cm}$ model. Arrows indicate weak peaks in the data (solid) or in the model (dashed) which indicate the $12 \mathrm{~cm}$ model is incorrect.

Figure S2. Observed calculated and difference plots from the structural refinement of $\mathrm{RbNdTa}_{2} \mathrm{O}_{7}$ against Synchrotron X-ray powder diffraction data. Top and middle-left plots show fits using an $I 2 \mathrm{~cm}$ model. For comparison the middle-right plot shows a fit using an Imam model bottom and the bottom plot shows a fit using a $P 2{ }_{1}$ am model. Arrows indicate weak peaks in the data (solid) or in the model (dashed) which indicate the $P 2{ }_{1}$ am model is incorrect.

Figure S3. Observed calculated and difference plots from the refinement, against neutron powder diffraction data collected from $\mathrm{CsNdTa}_{2} \mathrm{O}_{7}$, of structural models in space group $\mathrm{P} 2{ }_{1} \mathrm{am}, \mathrm{Imam}$ and $\mathrm{I} 2 \mathrm{~cm}$. Panels on the right show expanded plots in the region $1.2<\mathrm{d} / \AA<1.8$ highlighting the difference in the quality of the fits with the different models.

Figure S4. Observed calculated and difference plots from the refinement, against neutron powder diffraction data collected from $\mathrm{RbNdNb}_{2} \mathrm{O}_{7}$, of structural models in space group $\mathrm{P} 2_{1} \mathrm{am}$, Imam and $\mathrm{I} 2 \mathrm{~cm}$. Panels on the right show expanded plots in the region $1.2<\mathrm{d} / \AA<1.8$ highlighting the difference in the quality of the fits with the different models.

Figure S5. Observed calculated and difference plots from the refinement, against neutron powder diffraction data collected from $\mathrm{RbNdTa}_{2} \mathrm{O}_{7}$, of structural models in space group $\mathrm{P} 2{ }_{1}$ am, Imam and $\mathrm{I} 2 \mathrm{~cm}$, plotted as a function of d-spacing $(\AA)$. Panel on the right show expanded plots in the region $1.2<\mathrm{d} / \AA<1.8$ highlighting the difference in the quality of the fits with the different models. 


\section{Particle-size dependent second-harmonic response.}

Figure S6. Plot of SHG activity of $\mathrm{CsNdTa}_{2} \mathrm{O}_{7}$ as a function of particle size, compared to $\mathrm{KH}_{2} \mathrm{PO}_{4}(\mathrm{KDP})$ standard.

Figure S7. Plot of SHG activity of $\mathrm{RbNdTa}_{2} \mathrm{O}_{7}$ as a function of particle size, compared to $\mathrm{KH}_{2} \mathrm{PO}_{4}(\mathrm{KDP})$ standard.

\section{Refined strucutral data}

Figure S8. Observed, calculated and difference plots from the refinement of a structural model in space group $12 \mathrm{~cm}(\# 46)$ against neutron powder diffraction data collected from $\mathrm{RbNdNb}_{2} \mathrm{O}_{7}$ at $298 \mathrm{~K}\left(\chi^{2}=8.23\right)$. Top panel shows data from the $168^{\circ}$ detector bank, bottom panel from the $90^{\circ}$ detector bank.

Figure S9. Observed, calculated and difference plots from the refinement of a structural model in space group $P 2{ }_{1}$ am (\#26) against neutron powder diffraction data collected from $\mathrm{CsNdTa}_{2} \mathrm{O}_{7}$ at $298 \mathrm{~K}\left(\chi^{2}=5.63\right)$. Top panel shows data from the $168^{\circ}$ detector bank, bottom panel from the $90^{\circ}$ detector bank.

Figure S10. Observed, calculated and difference plots from the refinement of a structural model in space group $12 \mathrm{~cm}(\# 46)$ against neutron powder diffraction data collected from $\mathrm{RbNdTa}_{2} \mathrm{O}_{7}$ at $298 \mathrm{~K}$. Top panel shows data from the $168^{\circ}$ detector bank, bottom panel from the $90^{\circ}$ detector bank.

Table S4. Parameters from the structural refinement of $\mathrm{RbNdNb}_{2} \mathrm{O}_{7}$ against neutron powder diffraction data collected at $298 \mathrm{~K}$.

Table S5. Parameters from the structural refinement of $\mathrm{CsNdTa}_{2} \mathrm{O}_{7}$ against neutron powder diffraction data collected at $298 \mathrm{~K}$.

Table S6. Parameters from the structural refinement of $\mathrm{RbNdTa}_{2} \mathrm{O}_{7}$ against neutron powder diffraction data collected at $298 \mathrm{~K}$.

Table S7. Selected bond lengths from the refined structure of $\mathrm{RbNdNb}_{2} \mathrm{O}_{7}$

Table S8. Selected bond lengths from the refined structure of $\mathrm{CsNdTa}_{2} \mathrm{O}_{7}$

Table S9. Selected bond lengths from the refined structure of $\mathrm{RbNdTa}_{2} \mathrm{O}_{7}$ 


\section{Structural characterization of $\mathrm{CsNdTa}_{2} \mathrm{O}_{7}, \mathrm{RbNdNb}_{2} \mathrm{O}_{7}$ and $\operatorname{RbNdTa}_{2} \mathrm{O}_{7}$ using synchrotron $\mathrm{X}$-ray powder diffraction data vs. neutron powder diffraction data.}

Three structural models, each describing a different distorted $n=2$ Dion-Jacobson structure, were refined against synchrotron X-ray powder diffraction data collected from $\mathrm{CsNdTa}_{2} \mathrm{O}_{7}$, $\mathrm{RbNdNb}_{2} \mathrm{O}_{7}$ and $\mathrm{RbNdTa}_{2} \mathrm{O}_{7}$. Specifically models in space groups $P 2_{1}$ am (\#26), Imam (\#74) and $I 2 \mathrm{~cm}$ (\#46) which describe $\mathrm{a}^{-} \mathrm{ac}^{+}, \mathrm{a}^{-} \mathrm{a}^{-} /-\left(\mathrm{a}^{-} \mathrm{a}^{-0}\right)$ and $\mathrm{a}^{-} \mathrm{a}^{-} \mathrm{c}^{+} /-\left(\mathrm{a}^{-} \mathrm{ac}^{+}\right)$distortions respectively, were refined against the data to give the fitting statistics shown in Tables S1-S3.

\begin{tabular}{|c|c|c|c|c|c|c|c|c|}
\hline & \multicolumn{4}{|c|}{ Synchrotron X-ray } & \multicolumn{4}{c|}{ Neutron } \\
\hline Space group & $\chi^{2}$ & wRp (\%) & $\mathrm{Rp} \mathrm{( \% )}$ & $\begin{array}{c}\text { number of } \\
\text { variables }\end{array}$ & $\chi^{2}$ & wRp (\%) & $\mathrm{Rp} \mathrm{( \% )}$ & $\begin{array}{c}\text { number of } \\
\text { variables }\end{array}$ \\
\hline$P 2_{1}$ am (\#26) & 4.29 & 3.06 & 1.84 & 51 & 5.63 & 4.80 & 5.21 & 61 \\
\hline Imam (\#74) & 4.36 & 3.10 & 1.89 & 43 & 48.74 & 14.11 & 11.75 & 53 \\
\hline I2cm (\#46) & 4.33 & 3.07 & 1.87 & 51 & 47.53 & 13.95 & 11.43 & 61 \\
\hline
\end{tabular}

Table S1. Fitting statistics from the structural refinement of $\mathrm{CsNdTa}_{2} \mathrm{O}_{7}$ against synchrotron

$\mathrm{X}$-ray and neutron powder diffraction data.

\begin{tabular}{|c|c|c|c|c|c|c|c|c|}
\hline & \multicolumn{4}{|c|}{ Synchrotron X-ray } & \multicolumn{4}{|c|}{ Neutron } \\
\hline Space group & $\chi^{2}$ & wRp (\%) & $\mathrm{Rp} \mathrm{( \% )}$ & $\begin{array}{c}\text { number of } \\
\text { variables }\end{array}$ & $\chi^{2}$ & wRp (\%) & $\mathrm{Rp} \mathrm{( \% )}$ & $\begin{array}{c}\text { number of } \\
\text { variables }\end{array}$ \\
\hline P2 ${ }_{1}$ am (\#26) & 5.05 & 5.79 & 3.81 & 51 & 103.10 & 16.31 & 12.12 & 61 \\
\hline Imam (\#74) & 5.12 & 5.85 & 3.84 & 43 & 68.07 & 13.22 & 11.10 & 53 \\
\hline I2cm (\#46) & 4.97 & 5.76 & 3.78 & 51 & 8.23 & 6.31 & 6.25 & 61 \\
\hline
\end{tabular}

Table S2. Fitting statistics from the structural refinement of $\mathrm{RbNdNb}_{2} \mathrm{O}_{7}$ against synchrotron

$\mathrm{X}$-ray and neutron powder diffraction data.

\begin{tabular}{|c|c|c|c|c|c|c|c|c|}
\hline & \multicolumn{4}{|c|}{ Synchrotron X-ray } & \multicolumn{4}{c|}{ Neutron } \\
\hline Space group & $\chi^{2}$ & wRp (\%) & $\mathrm{Rp}(\%)$ & $\begin{array}{c}\text { number of } \\
\text { variables }\end{array}$ & $\chi^{2}$ & wRp (\%) & Rp (\%) & $\begin{array}{c}\text { number of } \\
\text { variables }\end{array}$ \\
\hline P2 ${ }_{1}$ am (\#26) & 6.81 & 3.78 & 2.33 & 51 & 86.69 & 15.63 & 11.63 & 61 \\
\hline Imam (\#74) & 6.87 & 3.81 & 2.36 & 43 & 40.59 & 10.70 & 9.56 & 53 \\
\hline I2cm (\#46) & 6.76 & 3.75 & 2.31 & 51 & 8.33 & 4.85 & 4.96 & 61 \\
\hline
\end{tabular}

Table S3. Fitting statistics from the structural refinement of $\mathrm{RbNdTa}_{2} \mathrm{O}_{7}$ against synchrotron $\mathrm{X}$-ray and neutron powder diffraction data.

Considering the fitting statistics from the refinements against the synchrotron X-ray powder diffraction data, it is impossible to state with any confidence which is the correct structure. While the $P 2_{1} a m$ model achieves the best statistical fit for $\mathrm{CsNdTa}_{2} \mathrm{O}_{7}$ and the $I 2 \mathrm{~cm}$ for $\mathrm{RbNdNb}_{2} \mathrm{O}_{7}$ and $\mathrm{RbNdTa}_{2} \mathrm{O}_{7}$, the margin of 'victory' is too small to be confident that these are the correct structures.

X-ray powder diffraction data are relatively insensitive to the distortions of Dion-Jacobson phases because the largest deformation of the lattice arises from the displacement of light oxide ions, which have small X-ray scattering cross sections. As a result the additional peaks observed in diffraction data, as the symmetry of the system is lowered from that of the $P 4 / \mathrm{mmm}$ aristotype, are extremely weak. Figure S1 shows fits to the synchrotron X-ray 
powder diffraction data collected from $\mathrm{CsNdTa}_{2} \mathrm{O}_{7}$ using a $P 2_{1}$ am model (shown to be correct by neutron powder diffraction) and an $I 2 \mathrm{~cm}$ model. It can be seen that the $P 2_{1} \mathrm{am}$ model accounts for a series of weak peaks that the $12 \mathrm{~cm}$ model does not, however the intensity of these 'additional' diffraction peaks is much less than $1 \%$ of the most intense peak in the pattern, so that while it is in principle possible to exclude the $12 \mathrm{~cm}$ model using these data, the fitting statistics of refinements using the two models are very similar. Furthermore, given the weakness of the 'additional' diffraction peaks, it is not possible to accurately quantify the magnitude of the oxide ion displacements, as the only information about the size of these displacements comes from the relative intensity of the 'additional' peaks which is hard to measure accurately, even with synchrotron radiation.

Figure S2 shows analogous fits to the synchrotron X-ray powder diffraction data collected from $\mathrm{RbNdTa}_{2} \mathrm{O}_{7}$ using an $12 \mathrm{~cm}$ model (shown to be correct by neutron powder diffraction), an Imam model and a $P 2{ }_{1} a m$ model. Again it can be seen that the features which differentiate between the two models are extremely weak. In addition, because the space groups $12 \mathrm{~cm}$ and Imam have the same extinction conditions, it can be seen that the only way to differentiate between the $I 2 \mathrm{~cm}$ and Imam models is by the relative intensity of the extremely weak 'additional' diffraction peaks, resulting in similar fitting statistics for refinements using these two models. Thus we can conclude that it is extremely difficult to accurately determine the symmetry and magnitude of the structural distortions of Dion-Jacobson phases from X-ray powder diffraction data alone.

In contrast, high-resolution neutron powder diffraction data are much more sensitive to the distortions of these phases. Tables S1-S3 list the fitting statistics for refinements using the $P 2_{1} \mathrm{am}$, Imam and $I 2 \mathrm{~cm}$ models against neutron powder diffraction data collected from $\mathrm{CsNdTa}_{2} \mathrm{O}_{7}, \mathrm{RbNdNb}_{2} \mathrm{O}_{7}$ and $\mathrm{RbNdTa}_{2} \mathrm{O}_{7}$. It can be seen in each case one model $\left(P 2_{1} a m\right.$ for $\mathrm{CsNdTa}_{2} \mathrm{O}_{7}$ and $I 2 \mathrm{~cm}$ for $\mathrm{RbNdNb}_{2} \mathrm{O}_{7}$ and $\left.\mathrm{RbNdTa}_{2} \mathrm{O}_{7}\right)$ is far superior to the other two. This is because the displacement of oxide ions leads to much larger changes in the observed diffraction data. This can be seen in Figures S3-S5 which show comparative fits for each of the three structural models $\left(P 2_{1} \mathrm{am}\right.$, Imam and $\left.I 2 \mathrm{~cm}\right)$ to the neutron diffraction data collected from each of the three samples. These data clearly and unambiguously show that $\mathrm{CsNdTa}_{2} \mathrm{O}_{7}$ adopts a $P 2_{1}$ am-type distortion while $\mathrm{RbNdNb}_{2} \mathrm{O}_{7}$ and $\mathrm{RbNdTa}_{2} \mathrm{O}_{7}$ adopt $I 2 \mathrm{~cm}$-type distortions. 

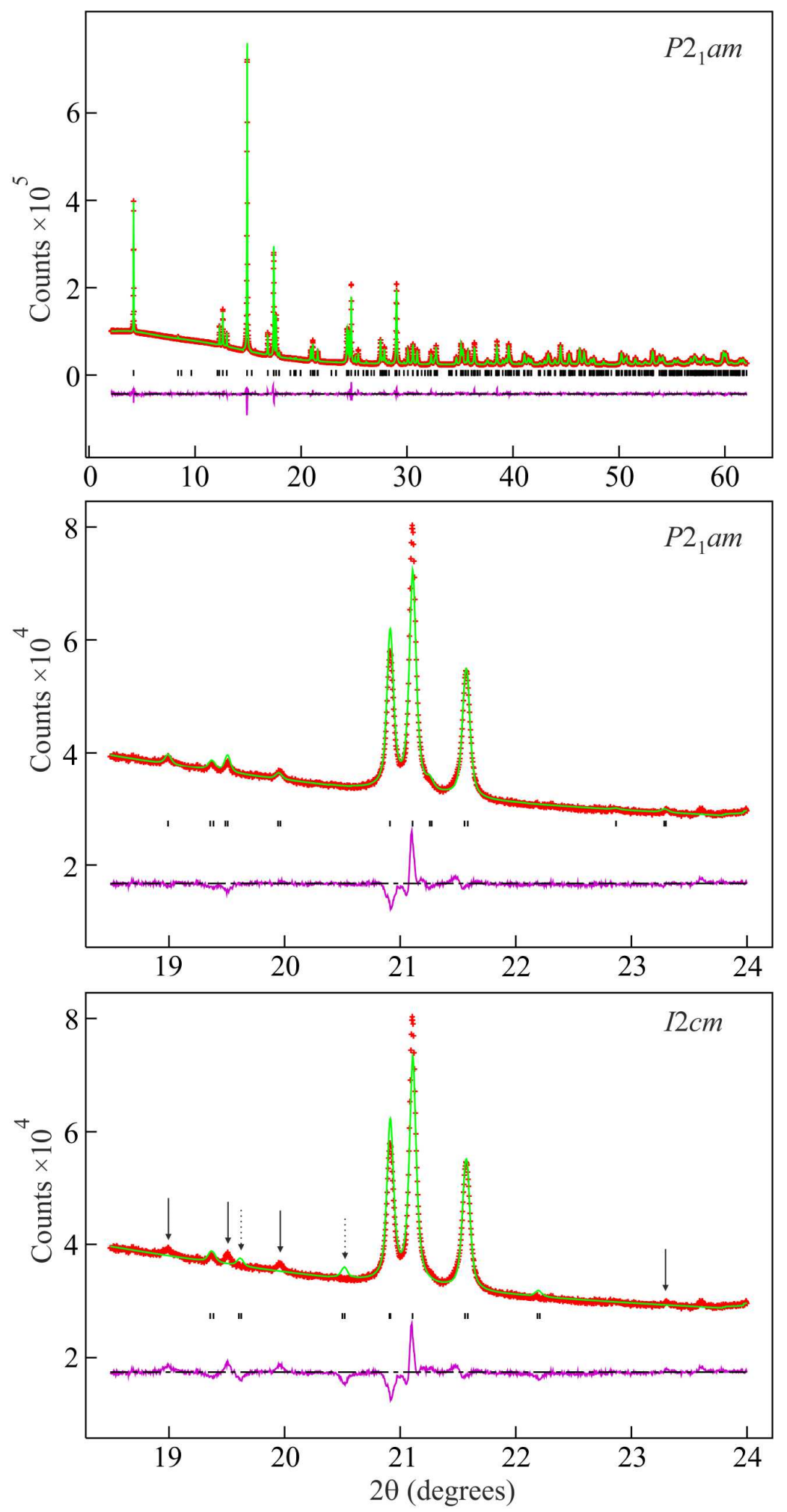

Figure S1. Observed calculated and difference plots from the structural refinement of $\mathrm{CsNdTa}_{2} \mathrm{O}_{7}$ against Synchrotron $\mathrm{X}$-ray powder diffraction data. Top and middle plots show fits using a $P 2{ }_{1} \mathrm{am}$ model. For comparison the bottom plot shows a fit using an $12 \mathrm{~cm}$ model. Arrows indicate weak peaks in the data (solid) or in the model (dashed) which indicate the $12 \mathrm{~cm}$ model is incorrect. 

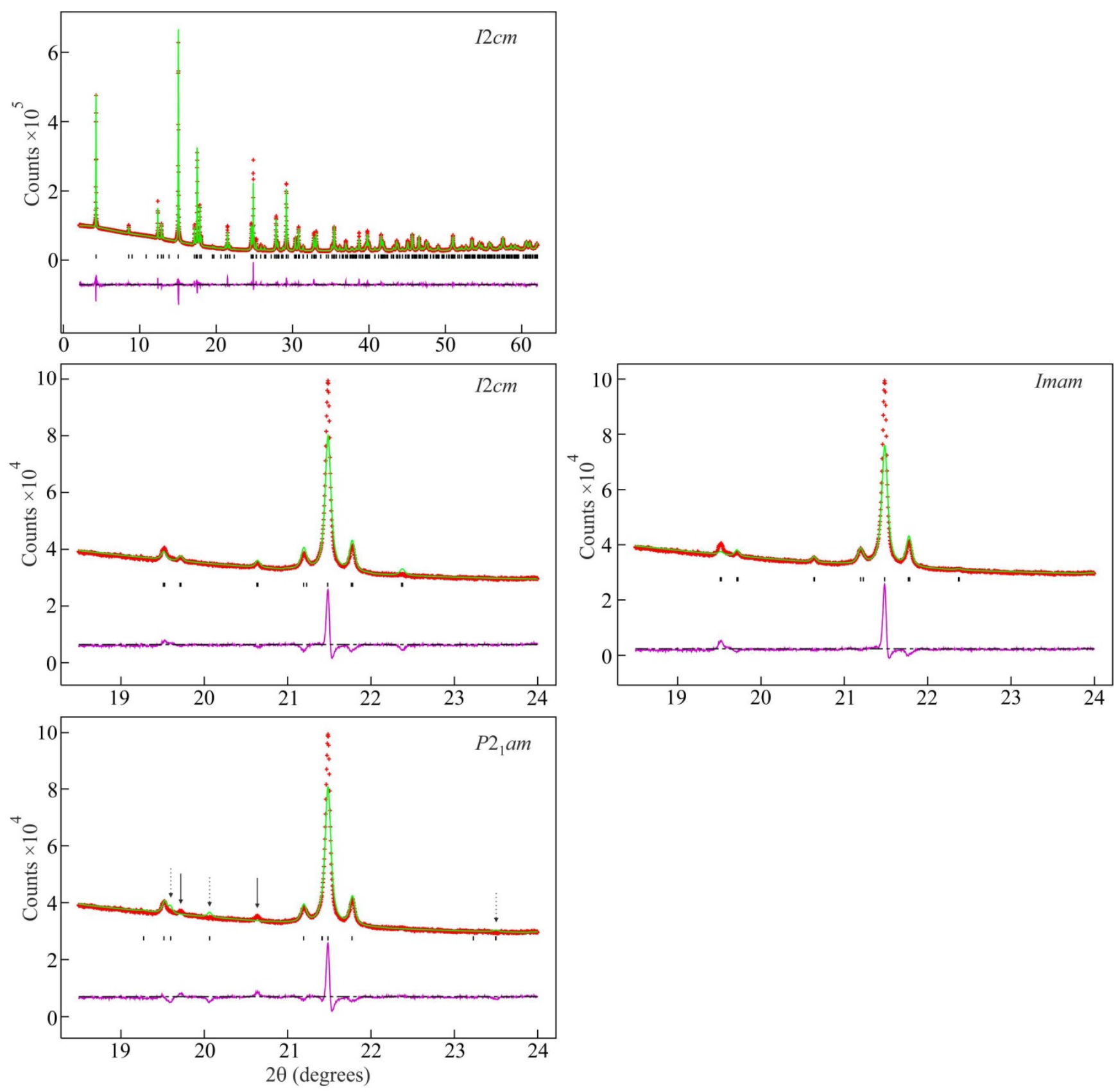

Figure S2. Observed calculated and difference plots from the structural refinement of $\mathrm{RbNdTa}_{2} \mathrm{O}_{7}$ against Synchrotron X-ray powder diffraction data. Top and middle-left plots show fits using an $I 2 \mathrm{~cm}$ model. For comparison the middle-right plot shows a fit using an Imam model bottom and the bottom plot shows a fit using a $P 2{ }_{1}$ am model. Arrows indicate weak peaks in the data (solid) or in the model (dashed) which indicate the $P 2{ }_{1} a m$ model is incorrect. 

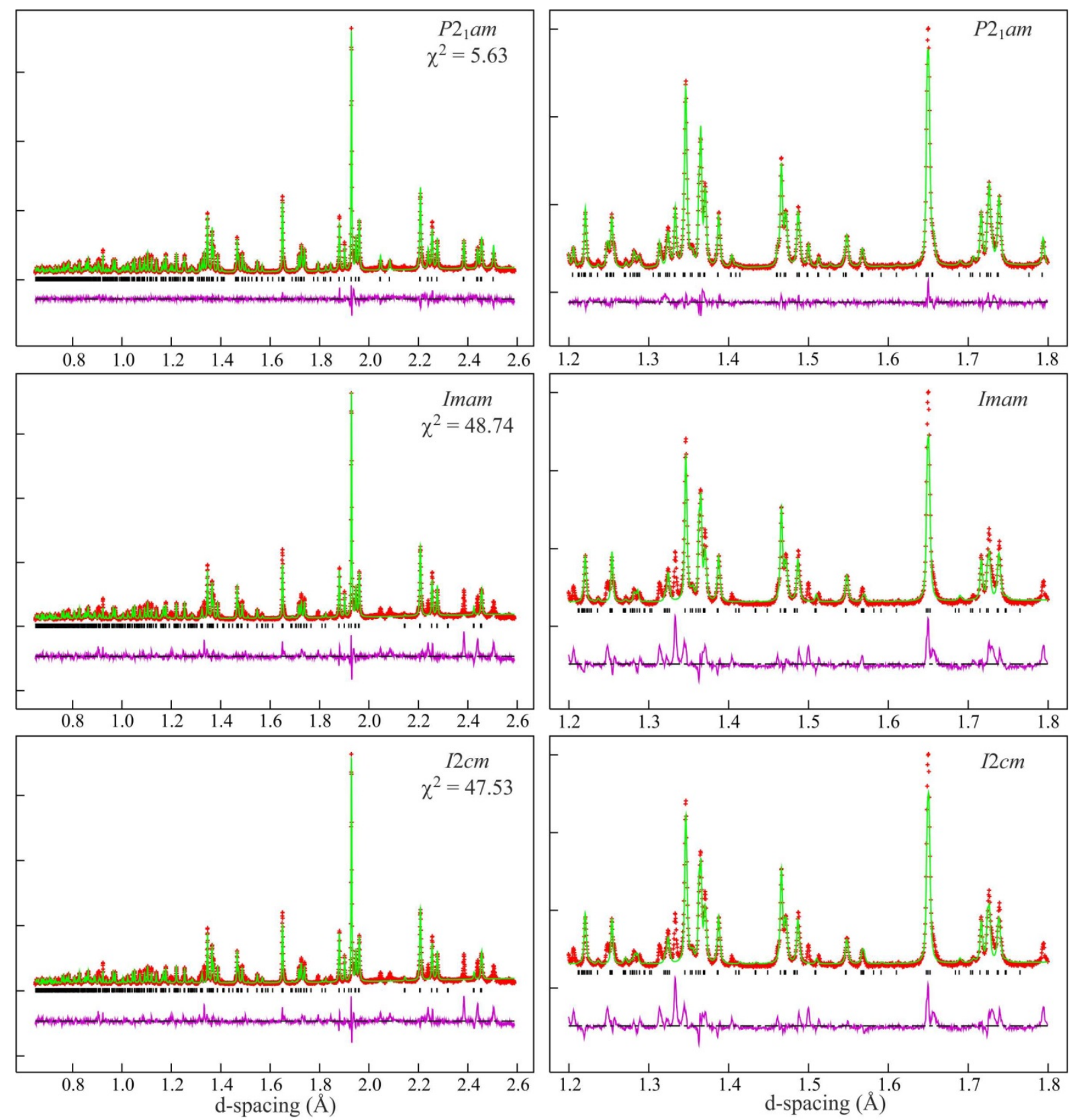

Figure S3. Observed calculated and difference plots from the refinement, against neutron powder diffraction data collected from $\mathrm{CsNdTa}_{2} \mathrm{O}_{7}$, of structural models in space group $\mathrm{P} 2{ }_{1} \mathrm{am}$, Imam and $\mathrm{I} 2 \mathrm{~cm}$. Panels on the right show expanded plots in the region $1.2<\mathrm{d} / \AA<$ 1.8 highlighting the difference in the quality of the fits with the different models. 


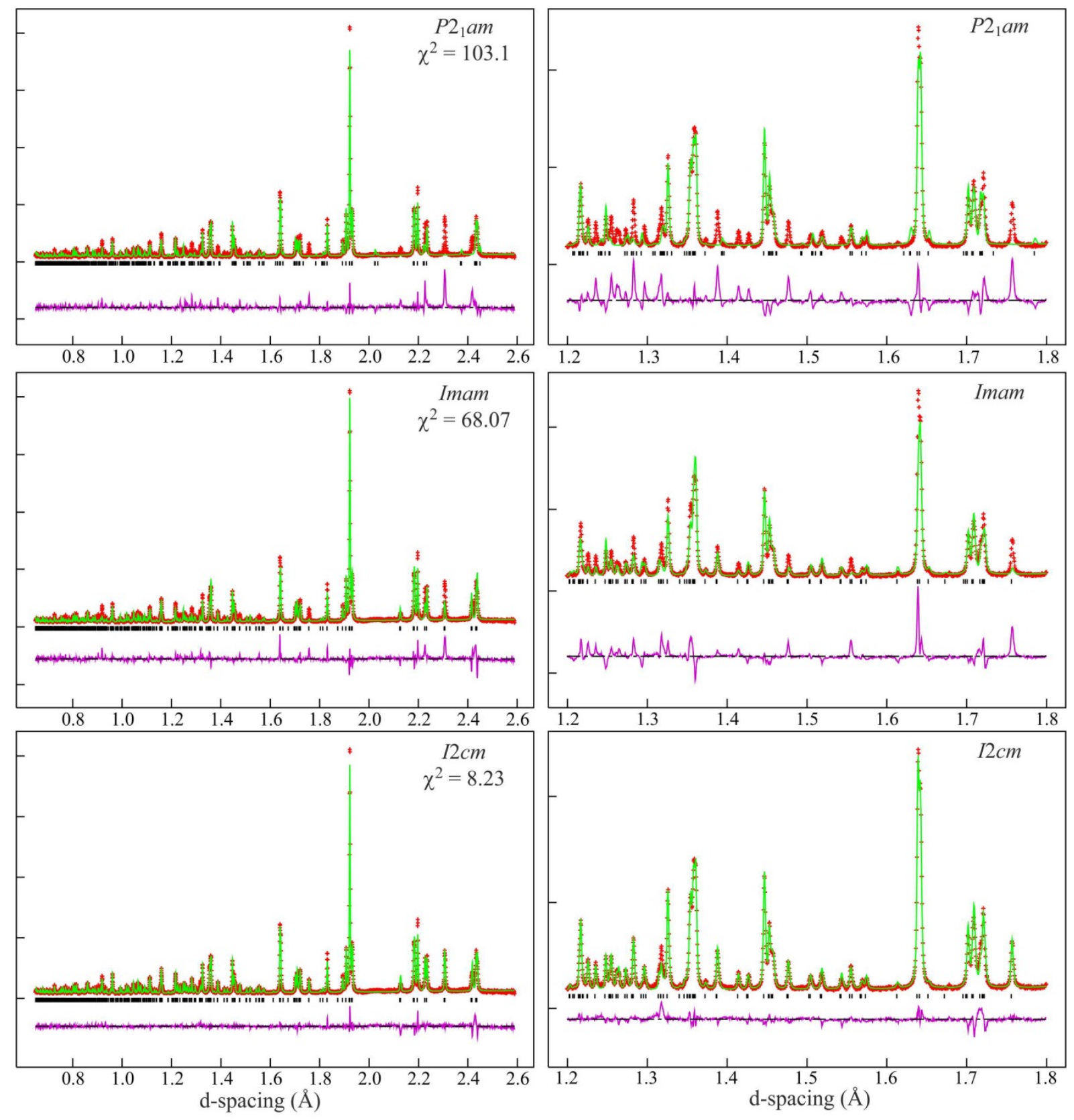

Figure S4. Observed calculated and difference plots from the refinement, against neutron powder diffraction data collected from $\mathrm{RbNdNb}_{2} \mathrm{O}_{7}$, of structural models in space group $\mathrm{P} 2{ }_{1} \mathrm{am}$, Imam and $\mathrm{I} 2 \mathrm{~cm}$. Panels on the right show expanded plots in the region $1.2<\mathrm{d} / \AA<$ 1.8 highlighting the difference in the quality of the fits with the different models. 


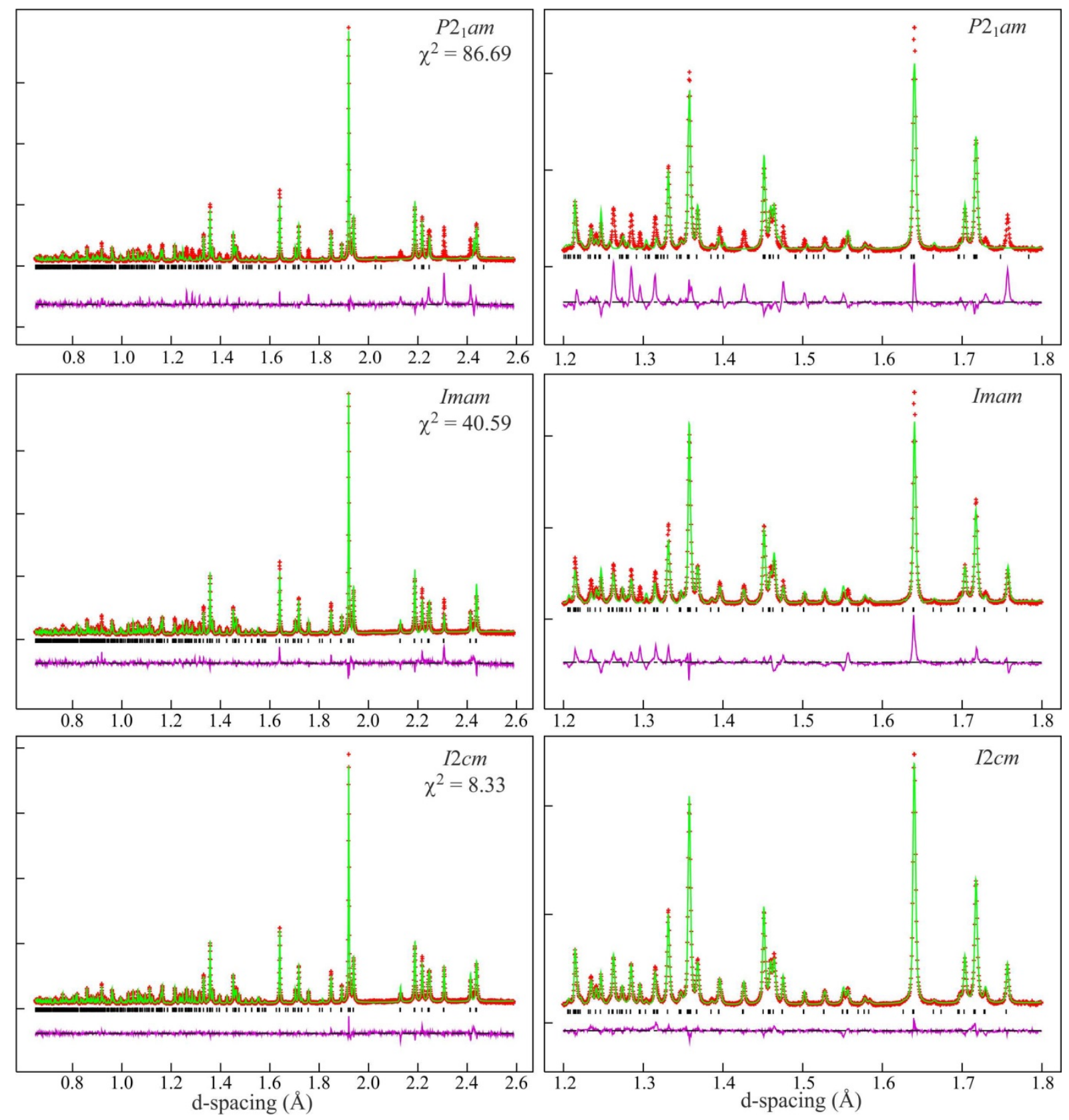

Figure S5. Observed calculated and difference plots from the refinement, against neutron powder diffraction data collected from $\mathrm{RbNdTa}_{2} \mathrm{O}_{7}$, of structural models in space group $\mathrm{P} 2{ }_{1} \mathrm{am}$, Imam and $\mathrm{I} 2 \mathrm{~cm}$, plotted as a function of d-spacing $(\AA)$. Panel on the right show expanded plots in the region $1.2<\mathrm{d} / \AA<1.8$ highlighting the difference in the quality of the fits with the different models. 
2. Particle-size dependent second-harmonic response

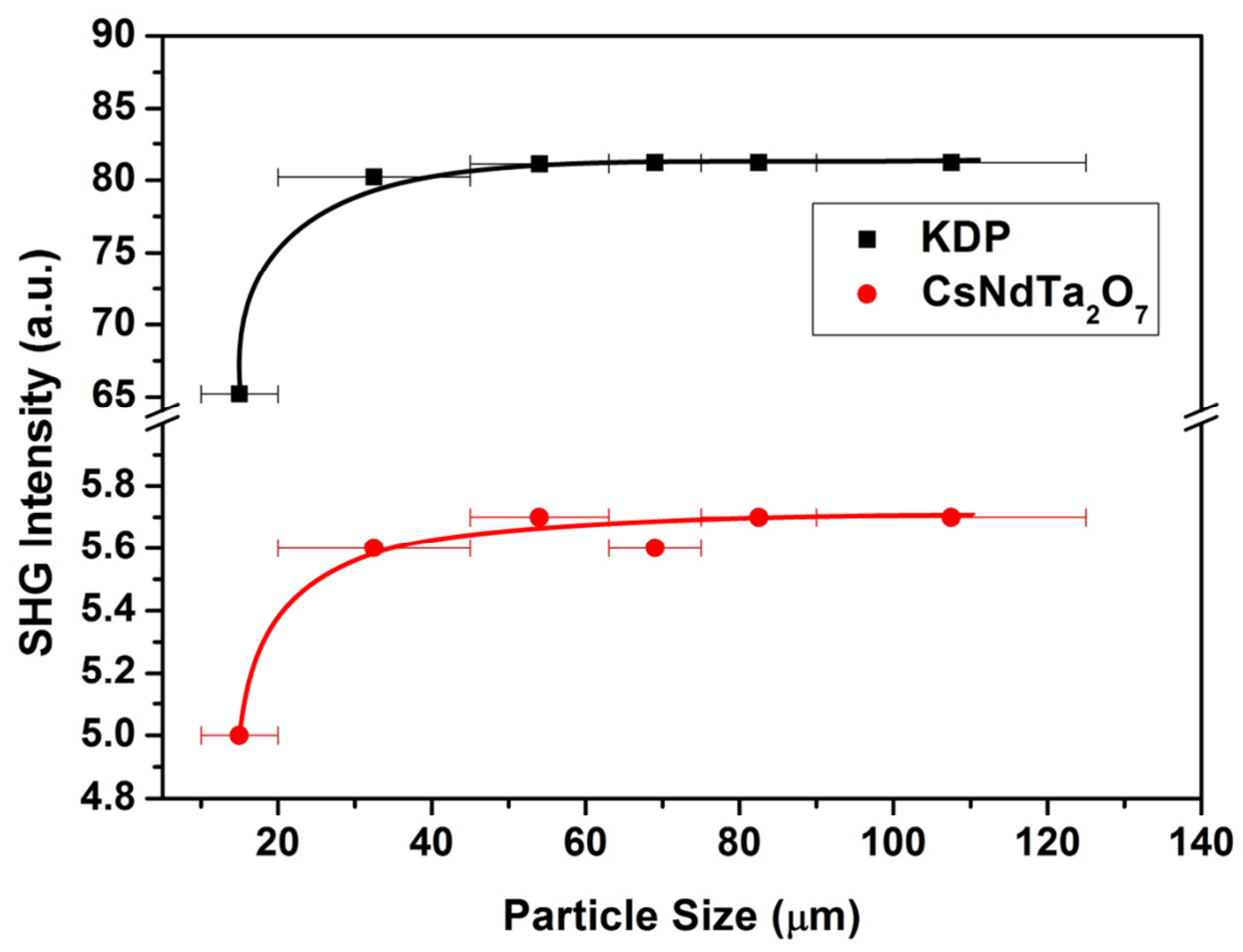

Figure S6. Plot of SHG activity of $\mathrm{CsNdTa}_{2} \mathrm{O}_{7}$ as a function of particle size, compared to $\mathrm{KH}_{2} \mathrm{PO}_{4}(\mathrm{KDP})$ standard.

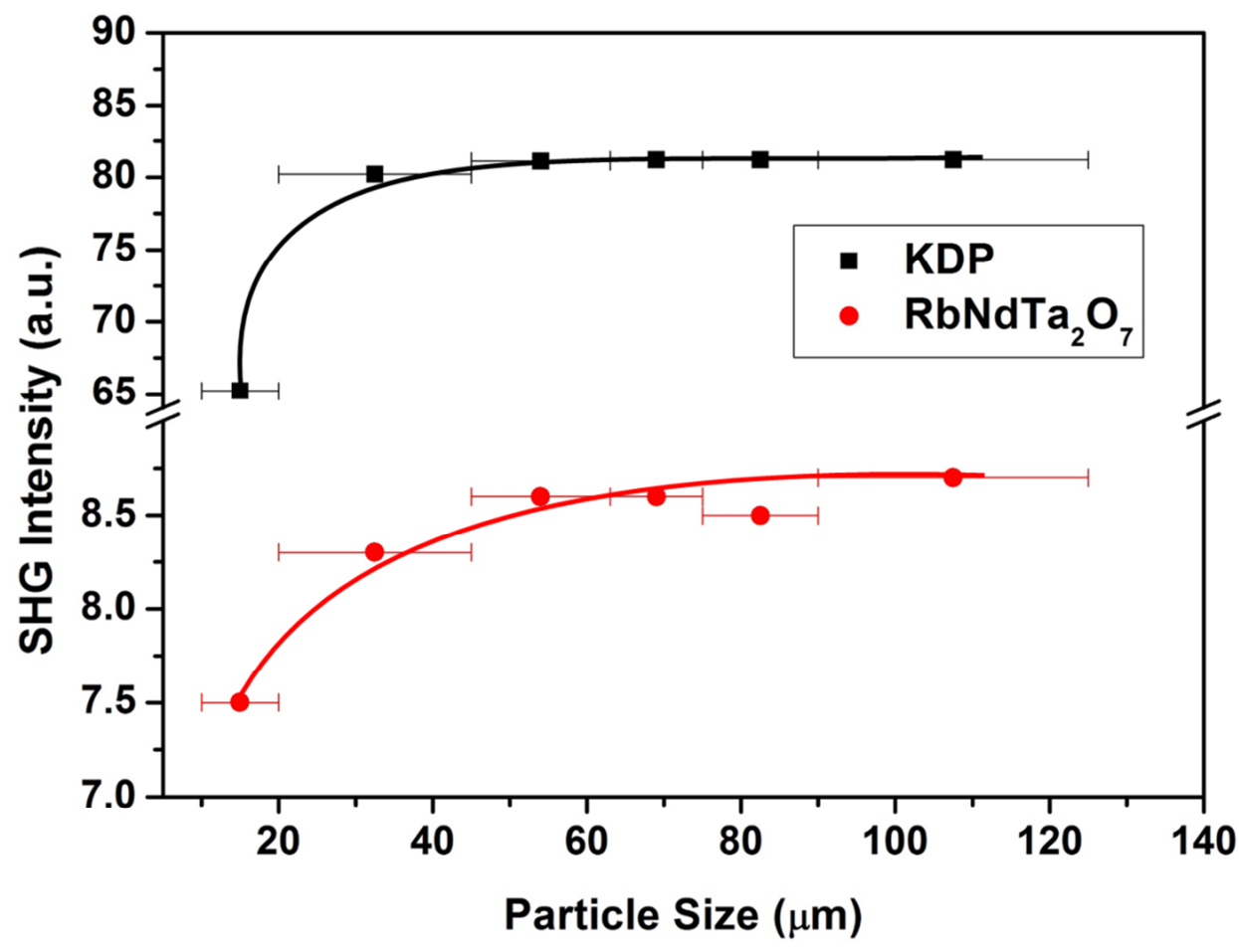

Figure S7. Plot of SHG activity of $\mathrm{RbNdTa}_{2} \mathrm{O}_{7}$ as a function of particle size, compared to $\mathrm{KH}_{2} \mathrm{PO}_{4}(\mathrm{KDP})$ standard. 


\section{Refined strucutral data}
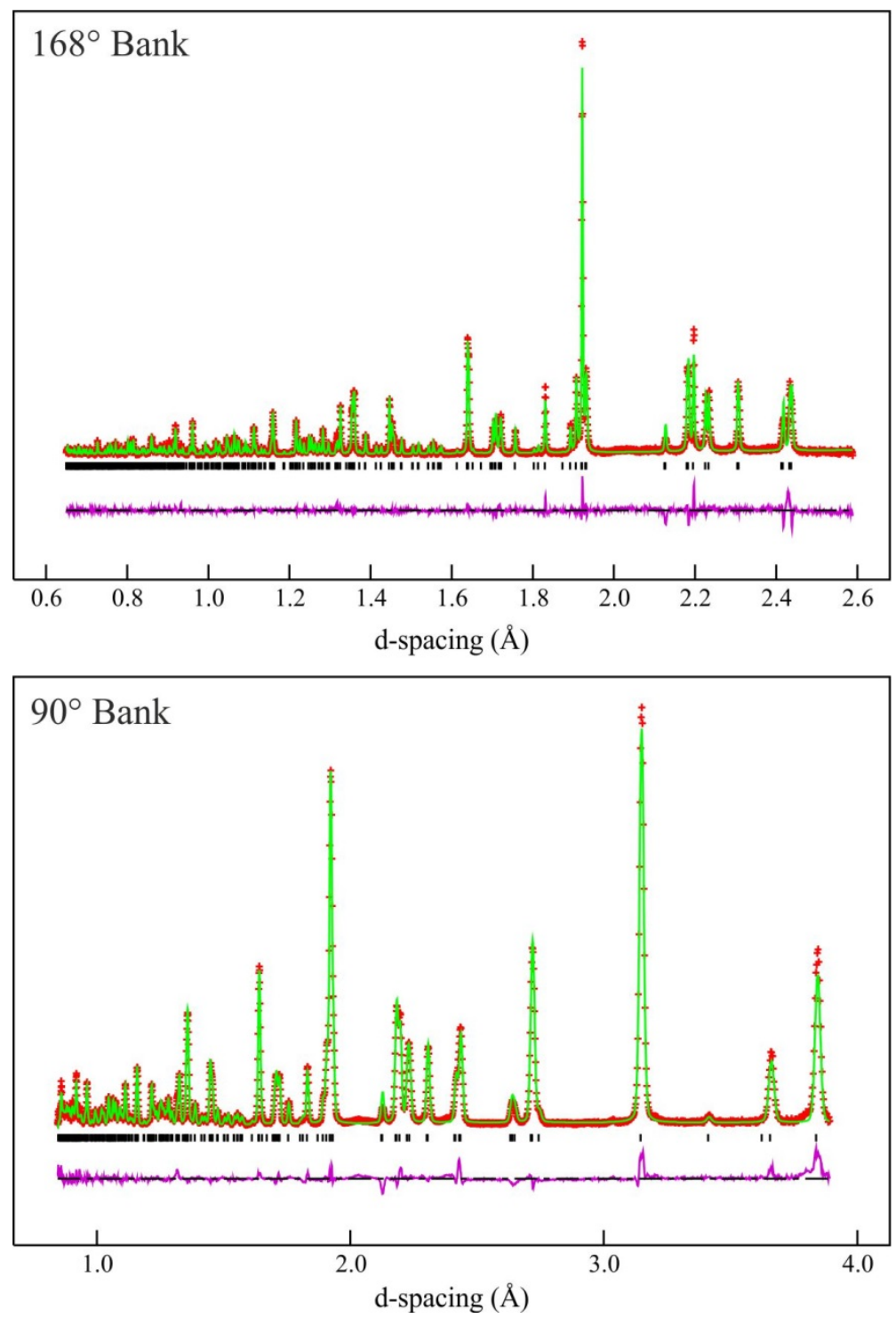

Figure S8. Observed, calculated and difference plots from the refinement of a structural model in space group $I 2 \mathrm{~cm}(\# 46)$ against neutron powder diffraction data collected from $\mathrm{RbNdNb}_{2} \mathrm{O}_{7}$ at $298 \mathrm{~K}\left(\chi^{2}=8.23\right)$. Top panel shows data from the $168^{\circ}$ detector bank, bottom panel from the $90^{\circ}$ detector bank. 

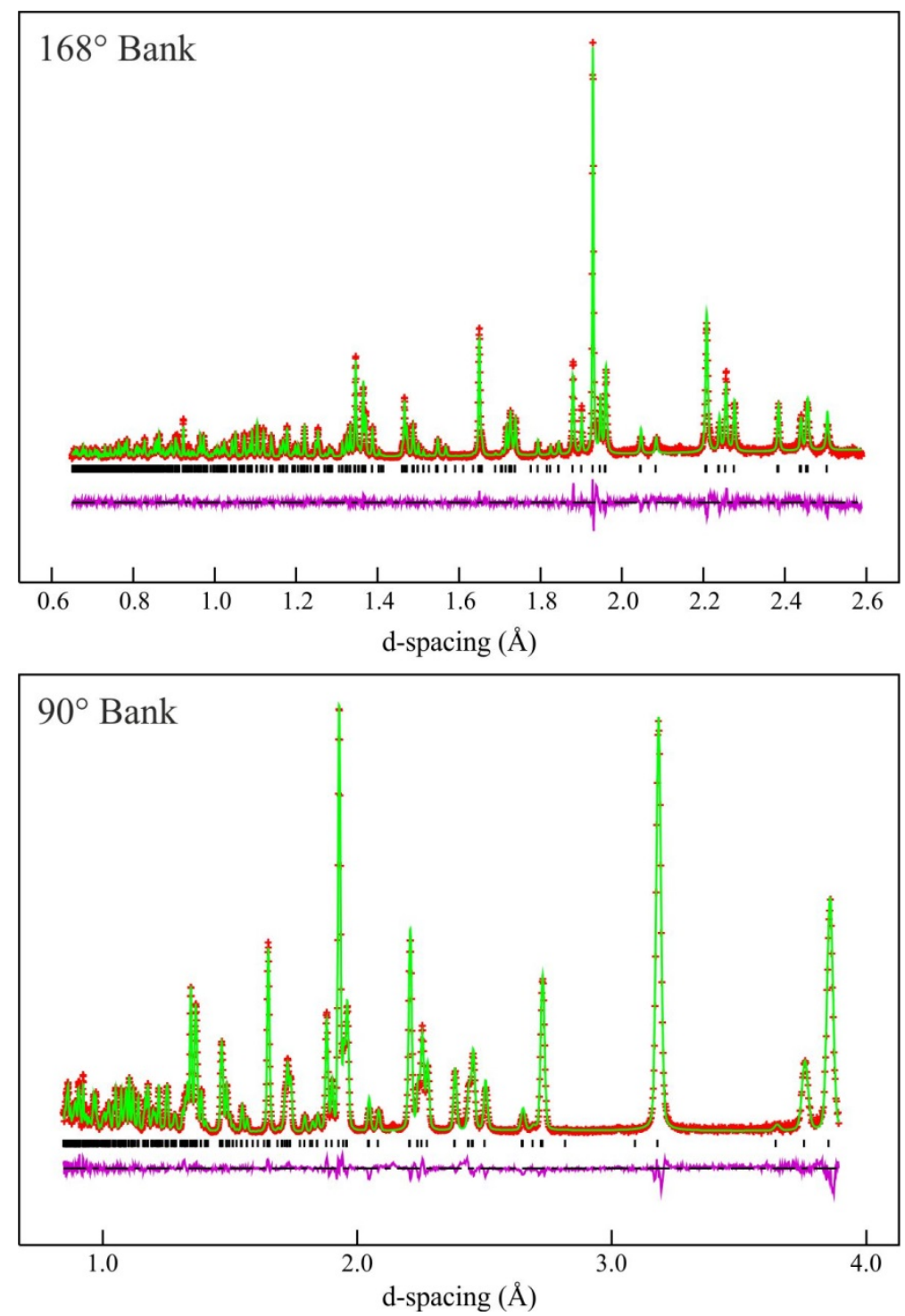

Figure S9. Observed, calculated and difference plots from the refinement of a structural model in space group $P 2{ }_{1}$ am (\#26) against neutron powder diffraction data collected from $\mathrm{CsNdTa}_{2} \mathrm{O}_{7}$ at $298 \mathrm{~K}\left(\chi^{2}=5.63\right)$. Top panel shows data from the $168^{\circ}$ detector bank, bottom panel from the $90^{\circ}$ detector bank. 

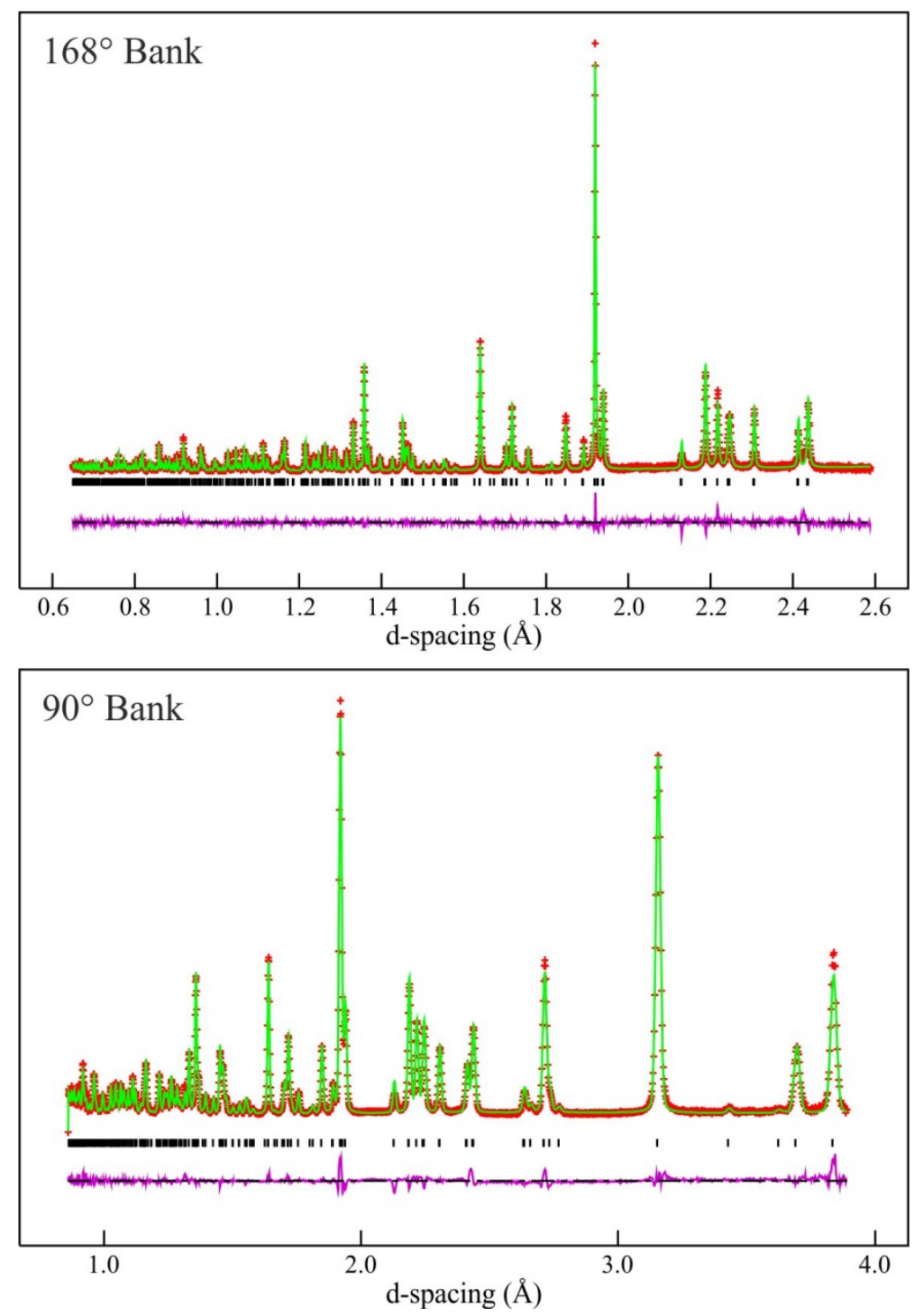

Figure S10. Observed, calculated and difference plots from the refinement of a structural model in space group $I 2 \mathrm{~cm}$ (\#46) against neutron powder diffraction data collected from $\mathrm{RbNdTa}_{2} \mathrm{O}_{7}$ at $298 \mathrm{~K}$. Top panel shows data from the $168^{\circ}$ detector bank, bottom panel from the $90^{\circ}$ detector bank. 


\begin{tabular}{|c|c|c|c|c|c|}
\hline Atom & site & $x$ & $y$ & $z$ & $\mathrm{U}_{\text {iso }}\left(\AA^{3}\right)$ \\
\hline $\mathrm{Rb}(1)$ & $4 a$ & $0.7521(12)$ & 0 & 0 & $0.0364(4)$ \\
\hline $\mathrm{Nd}(1)$ & $4 b$ & $0.7541(10)$ & $0.9995(4)$ & $1 / 4$ & $0.0105(3)$ \\
\hline $\mathrm{Nb}(1)$ & $8 c$ & $0.2454(6)$ & $0.0009(3)$ & $0.35323(5)$ & $0.0124(3)$ \\
\hline $\mathrm{O}(1)$ & $8 c$ & $0.9943(7)$ & $0.7597(8)$ & $0.32438(8)$ & $0.0197(4)$ \\
\hline $\mathrm{O}(2)$ & $8 c$ & $0.0700(5)$ & $0.2975(5)$ & $0.34909(10)$ & $0.0238(5)$ \\
\hline $\mathrm{O}(3)$ & $8 c$ & $0.7447(9)$ & $0.5527(4)$ & $0.43222(8)$ & $0.0218(5)$ \\
\hline $\mathrm{O}(4)$ & $4 b$ & $0.7192(8)$ & $0.4269(5)$ & $1 / 4$ & $0.0176(9)$ \\
\hline \multicolumn{6}{|c|}{$\begin{array}{l}\mathrm{RbNdNb}_{2} \mathrm{O}_{7}-\text { space group I2cm }(\# 46) \\
b=5.4278(1) \AA, c=21.9625(4) \AA, \text { volume }=648.65(4) \AA^{3} \\
\text { Formula weight: } 527.51 \mathrm{~g} \mathrm{~mol}^{-1}, \mathrm{Z}=4 \\
\text { Radiation source: Neutron Time of flight } \\
\quad \text { Temperature: } 298 \mathrm{~K} \\
\chi^{2}=8.23, \mathrm{wRp}=6.31 \%, \mathrm{Rp}=6.25 \%\end{array}$} \\
\hline
\end{tabular}

Table S4. Parameters from the structural refinement of $\mathrm{RbNdNb}_{2} \mathrm{O}_{7}$ against neutron powder diffraction data collected at $298 \mathrm{~K}$.

\begin{tabular}{|c|c|c|c|c|c|}
\hline Atom & site & $x$ & $y$ & $z$ & $\mathrm{U}_{\text {iso }}\left(\AA^{3}\right)$ \\
\hline $\operatorname{Cs}(1)$ & $2 b$ & $0.2556(9)$ & $0.2358(6)$ & $1 / 2$ & $0.0136(3)$ \\
\hline $\mathrm{Nd}(1)$ & $2 a$ & $0.2740(5)$ & $0.2456(3)$ & 0 & $0.0033(3)$ \\
\hline $\mathrm{Ta}(1)$ & $4 c$ & $0.7493(4)$ & $0.2521(3)$ & $0.1997(1)$ & $0.0050(3)$ \\
\hline $\mathrm{O}(1)$ & $4 c$ & $0.5128(6)$ & $0.5184(6)$ & $0.1447(1)$ & $0.0126(4)$ \\
\hline $\mathrm{O}(2)$ & $4 c$ & $0.9509(5)$ & $0.9551(5)$ & $0.1835(1)$ & $0.0140(5)$ \\
\hline $\mathrm{O}(3)$ & $4 c$ & $0.7511(6)$ & $0.2926(3)$ & $0.3563(1)$ & $0.0118(4)$ \\
\hline $\mathrm{O}(4)$ & $2 a$ & $0.7318(9)$ & $0.1841(4)$ & 0 & $0.0095(6)$ \\
\hline \multicolumn{6}{|c|}{$\begin{array}{l}\mathrm{CsNdTa}_{2} \mathrm{O}_{7}-\text { space group P21am }(\# 26) \\
b=5.4494(1) \AA, c=11.2754(2) \AA \text {, volume }=335.41(1) \AA^{3} \\
\text { Formula weight: } 751.03 \mathrm{~g} \mathrm{~mol}^{-1}, \mathrm{Z}=2 \\
\text { Radiation source: Neutron Time of flight } \\
\quad \text { Temperature: } 298 \mathrm{~K} \\
\quad \chi^{2}=5.63, \mathrm{wRp}=4.8 \%, \mathrm{Rp}=5.2 \%\end{array}$} \\
\hline
\end{tabular}

Table S5. Parameters from the structural refinement of $\mathrm{CsNdTa}_{2} \mathrm{O}_{7}$ against neutron powder diffraction data collected at $298 \mathrm{~K}$. 


\begin{tabular}{|c|c|c|c|c|c|}
\hline Atom & site & $x$ & $y$ & $z$ & $\mathrm{U}_{\text {iso }}\left(\AA^{3}\right)$ \\
\hline $\mathrm{Rb}(1)$ & $4 a$ & $0.7387(7)$ & 0 & 0 & $0.0318(3)$ \\
\hline $\mathrm{Nd}(1)$ & $4 b$ & $0.7279(5)$ & $0.0034(3)$ & $1 / 4$ & $0.0071(3)$ \\
\hline $\mathrm{Ta}(1)$ & $8 c$ & $0.2491(4)$ & $0.9993(3)$ & $0.35261(3)$ & $0.0044(2)$ \\
\hline $\mathrm{O}(1)$ & $8 c$ & $0.9851(5)$ & $0.7710(5)$ & $0.32396(6)$ & $0.0142(3)$ \\
\hline $\mathrm{O}(2)$ & $8 c$ & $0.0590(4)$ & $0.2938(5)$ & $0.34500(7)$ & $0.0175(4)$ \\
\hline $\mathrm{O}(3)$ & $8 c$ & $0.7457(6)$ & $0.5492(3)$ & $0.43198(5)$ & $0.0163(3)$ \\
\hline $\mathrm{O}(4)$ & $4 b$ & $0.7697(8)$ & $0.4318(4)$ & $1 / 4$ & $0.0144(6)$ \\
\hline \multicolumn{6}{|c|}{$\begin{array}{l}\mathrm{RbNdTa}_{2} \mathrm{O}_{7}-\text { space group I2cm }(\# 46) \\
b=5.4241(1) \AA, c=22.1683(3) \AA \text {, volume }=652.98(3) \AA^{3} \\
\text { Formula weight: } 703.59 \mathrm{~g} \mathrm{~mol}^{-1}, \mathrm{Z}=4 \\
\text { Radiation source: Neutron Time of flight } \\
\quad \text { Temperature: } 298 \mathrm{~K} \\
\chi^{2}=8.33, \mathrm{wRp}=4.85 \%, \mathrm{Rp}=4.96 \%\end{array}$} \\
\hline
\end{tabular}

Table S6. Parameters from the structural refinement of $\mathrm{RbNdTa}_{2} \mathrm{O}_{7}$ against neutron powder diffraction data collected at $298 \mathrm{~K}$.

\begin{tabular}{|c|c|c|c|}
\hline Cation & Anion & length $(\AA)$ & BVS \\
\hline \multirow[t]{4}{*}{$\mathrm{Rb}(1)$} & $\mathrm{O}(3) \times 2$ & $2.848(2)$ & \multirow[t]{4}{*}{$\mathrm{Rb}+0.912$} \\
\hline & $\mathrm{O}(3) \times 2$ & $3.079(8)$ & \\
\hline & $\mathrm{O}(3) \times 2$ & $3.150(8)$ & \\
\hline & $\mathrm{O}(3) \times 2$ & $3.349(2)$ & \\
\hline \multirow[t]{8}{*}{$\mathrm{Nd}(1)$} & $\mathrm{O}(1) \times 2$ & $2.464(5)$ & \multirow[t]{8}{*}{$\mathrm{Nd}+2.99$} \\
\hline & $\mathrm{O}(1) \times 2$ & $2.578(5)$ & \\
\hline & $\mathrm{O}(2) \times 2$ & $2.637(3)$ & \\
\hline & $\mathrm{O}(2) \times 2$ & $3.210(4)$ & \\
\hline & $\mathrm{O}(4)$ & $2.328(4)$ & \\
\hline & $\mathrm{O}(4)$ & $2.562(7)$ & \\
\hline & $\mathrm{O}(4)$ & $2.938(7)$ & \\
\hline & $\mathrm{O}(4)$ & $3.114(3)$ & \\
\hline \multirow[t]{6}{*}{$\mathrm{Nb}(1)$} & $\mathrm{O}(1)$ & $1.996(5)$ & \multirow[t]{6}{*}{$\mathrm{Nb}+5.05$} \\
\hline & $\mathrm{O}(1)$ & $2.058(5)$ & \\
\hline & $\mathrm{O}(2)$ & $1.874(4)$ & \\
\hline & $\mathrm{O}(2)$ & $2.080(4)$ & \\
\hline & $\mathrm{O}(3)$ & $1.759(2)$ & \\
\hline & $\mathrm{O}(4)$ & $2.305(1)$ & \\
\hline
\end{tabular}

Table S7. Selected bond lengths from the refined structure of $\mathrm{RbNdNb}_{2} \mathrm{O}_{7}$ 


\begin{tabular}{|c|c|c|c|}
\hline Cation & Anion & length $(\AA)$ & BVS \\
\hline \multirow[t]{4}{*}{$\operatorname{Cs}(1)$} & $\mathrm{O}(3) \times 2$ & $3.038(4)$ & \multirow[t]{4}{*}{$\mathrm{Cs}+1.06$} \\
\hline & $\mathrm{O}(3) \times 2$ & $3.168(5)$ & \\
\hline & $\mathrm{O}(3) \times 2$ & $3.210(5)$ & \\
\hline & $\mathrm{O}(3) \times 2$ & $3.304(4)$ & \\
\hline \multirow[t]{8}{*}{$\mathrm{Nd}(1)$} & $\mathrm{O}(1) \times 2$ & $2.520(4)$ & \multirow[t]{8}{*}{$\mathrm{Nb}+3.07$} \\
\hline & $\mathrm{O}(1) \times 2$ & $2.533(2)$ & \\
\hline & $\mathrm{O}(2) \times 2$ & $2.564(4)$ & \\
\hline & $\mathrm{O}(2) \times 2$ & $3.147(3)$ & \\
\hline & $\mathrm{O}(4)$ & $2.354(4)$ & \\
\hline & $\mathrm{O}(4)$ & $2.521(6)$ & \\
\hline & $\mathrm{O}(4)$ & $2.979(6)$ & \\
\hline & $\mathrm{O}(4)$ & $3.115(3)$ & \\
\hline \multirow[t]{6}{*}{$\mathrm{Ta}(1)$} & $\mathrm{O}(1)$ & $2.004(4)$ & \multirow[t]{6}{*}{$\mathrm{Ta}+5.06$} \\
\hline & $\mathrm{O}(1)$ & $2.039(4)$ & \\
\hline & $\mathrm{O}(2)$ & $1.966(3)$ & \\
\hline & $\mathrm{O}(2)$ & $1.990(3)$ & \\
\hline & $\mathrm{O}(3)$ & $1.779(2)$ & \\
\hline & $\mathrm{O}(4)$ & $2.285(1)$ & \\
\hline
\end{tabular}

Table S8. Selected bond lengths from the refined structure of $\mathrm{CsNdTa}_{2} \mathrm{O}_{7}$

\begin{tabular}{|c|c|c|c|}
\hline Cation & Anion & length $(\AA)$ & BVS \\
\hline \multirow[t]{4}{*}{$\mathrm{Rb}(1)$} & $\mathrm{O}(3) \times 2$ & $2.873(2)$ & \multirow[t]{4}{*}{$\mathrm{Rb}+0.88$} \\
\hline & $\mathrm{O}(3) \times 2$ & $3.084(5)$ & \\
\hline & $\mathrm{O}(3) \times 2$ & $3.150(5)$ & \\
\hline & $\mathrm{O}(3) \times 2$ & $3.339(2)$ & \\
\hline \multirow[t]{8}{*}{$\mathrm{Nd}(1)$} & $\mathrm{O}(1) \times 2$ & $2.496(3)$ & \multirow[t]{8}{*}{$\mathrm{Nd}+3.09$} \\
\hline & $\mathrm{O}(1) \times 2$ & $2.577(3)$ & \\
\hline & $\mathrm{O}(2) \times 2$ & $2.547(2)$ & \\
\hline & $\mathrm{O}(2) \times 2$ & $3.186(3)$ & \\
\hline & $\mathrm{O}(4)$ & $2.335(3)$ & \\
\hline & $\mathrm{O}(4)$ & $2.513(5)$ & \\
\hline & $\mathrm{O}(4)$ & $2.963(4)$ & \\
\hline & $\mathrm{O}(4)$ & $3.109(3)$ & \\
\hline \multirow[t]{6}{*}{$\mathrm{Ta}(1)$} & $\mathrm{O}(1)$ & $1.998(3)$ & \multirow[t]{6}{*}{$\mathrm{Ta}+5.10$} \\
\hline & $\mathrm{O}(1)$ & $2.048(3)$ & \\
\hline & $\mathrm{O}(2)$ & $1.909(3)$ & \\
\hline & $\mathrm{O}(2)$ & $2.030(£)$ & \\
\hline & $\mathrm{O}(3)$ & $1.779(1)$ & \\
\hline & $\mathrm{O}(4)$ & $2.308(1)$ & \\
\hline
\end{tabular}

Table S9. Selected bond lengths from the refined structure of $\mathrm{RbNdTa}_{2} \mathrm{O}_{7}$ 